\title{
Turismo: buceo y conservación
}

DOI: $10.22403 /$ UQROOMX/TYP01/05

Luis Carlos Santander Botello*

José Rubén Bacab Sánchez

María del Carmen Pérez Ramírez

Resumen

En forma breve y general se presentan tres elementos relevantes para el análisis de los impactos del buceo turístico en arrecifes coralinos: la sinergia de la industria turística, la importancia del turismo de buceo y la problemática de la capacidad de carga de los arrecifes coralinos en Cozumel, México.

Palabras $\mid$ Cozumel, buceo, capacidad de carga, arrecifes.

*Universidad de Quintana Roo / Isant@correo.uqroo.mx

*Universidad de Quintana Roo / maperez@correo.uqroo.mx 
Turismo: buceo y

conservación

\section{El turismo de buceo}

Dinámica de la industria turística y del turismo de buceo; turismo de buceo y conservación de arrecifes coralinos, o turismo sustentable en arrecifes coralinos, es la línea de un proyecto de investigación que en la Universidad de Quintana Roo se viene realizando con el Parque Nacional Arrecifes de Cozumel y que a continuación se contextualiza y describe.

El turismo es considerado como el mayor componente del comercio mundial, superando las exportaciones de los sectores automotriz y de transportes, así como al de productos del petróleo. La industria turística representó en el 2000 casi II\% del Producto Mundial Bruto. Asimismo, da empleo a más de $8 \%$ de la población laboral del planeta y se espera que genere 5.5 millones de empleos por año en las primeras dos décadas de este siglo; su inversión total alcanza casi $9 \%$ de todas las inversiones de capital en el mundo (Santander, 2003; ONU, 1999). Esta masiva industria está dominada por las sinergias de la globalización y por los países desarrollados. En concordancia con este proceso, y no en modo antagónico, se ha venido desarrollando el turismo sustentable.

Por su parte, el turismo de buceo es una industria global con presencia en 91 países. El buceo tiene un crecimiento exponencial: de 1985 a 1995 el número de buzos que visitó la Gran Barrera en Australia pasó de I.I millones a 10 millones (Spalding, 200 I: 10). El 60\% de los turistas internacionales de buceo selecciona al Caribe como su destino de vacaciones. Se estima que para el año 2005 el buceo generará, en el Caribe, ingresos por I 200 millones de dólares (UNEP, 200 I: II).

Por lo que respecta a Cozumel, el Instituto Nacional de Ecología estima que cerca de $70 \%$ de los visitantes a la isla tiene como principal motivación el buceo (INE, 1997). Consecuentemente:

el deterioro de los arrecifes influye directa e indirectamente en la economía local ya que la mayoría de las actividades productivas están asociadas al buceo [...] [Por tanto] se requieren medidas de protección más efectivas, ya que a pesar de que al turista se le explican brevemente las condiciones y reglamentación del área, durante las inmersiones ocurren contactos involuntarios o negligentes; $y$ dado el creciente número de prestadores de servicios, estos 
Santander Botello

Bacab Sánchez

Pérez Ramírez

contactos irán en aumento hasta llegar a poner en peligro la integridad de los arrecifes [INE, 1998: 59].

Turismo e indicadores de sustentabilidad.

Arrecifes y capacidad soporte de buzos

El "Capítulo I7" de la Agenda 2 I establece que deben fijarse limitaciones en la utilización de los arrecifes de coral (ONU, 1992). En este contexto, las áreas marinas protegidas (AMP) se han convertido en una estrategia importante en la conciliación o armonía entre desarrollo turístico y conservación de arrecifes. Existen en el mundo alrededor de 600 AMP que contienen arrecifes coralinos (Spalding, 200I: I0). En el Caribe ampliado existen alrededor de 300 áreas marinas y costeras protegidas; sin embargo, en cerca de $70 \%$ de éstas los programas de manejo no logran los objetivos de conservación debido, entre otras causas, a prácticas turísticas no sustentables, una de las cuales es el exceso de visitantes en los sitios de buceo (UNEP, s/f). Por su parte, la Organización Mundial del Turismo (OMT) ha promovido la sustentabilidad para el desarrollo de la industria turística, enfatizando la importancia de indicadores específicos sobre el impacto directo en el aprovechamiento de los recursos.

Respecto a la capacidad soporte de buceo recreativo que tienen los arrecifes coralinos, el Programa de las Naciones Unidas para el Medio Ambiente (PNUMA O UNEP, por sus siglas en inglés) analizó estudios realizados en Australia, Florida, Egipto, Islas Maldivias, Kenia,Antillas Holandesas e Islas Vírgenes y con reservas aceptó la recomendación general de que el nivel que un sitio resiste es de 5000 a 6000 buzos por año; rebasando ese número la degradación producida por contacto directo de los buzos con el coral y otros organismos vivos empieza a ser rápidamente observable (UNEP 200 I: 17). Sin embargo, el mismo reporte establece que fijar la capacidad soporte para sitios específicos requiere tomar en cuenta la incidencia de factores como: tipo de arrecife, tipos de coral, condiciones para el buceo, nivel de experiencia de los buzos, capacidad de los operadores para concientizar a sus clientes en materia de protección ambiental, entre otros.

Hasta 1992 no existían en México iniciativas específicas para la conservación de arrecifes coralinos. Sin embargo, a partir de 1995 se ha generado un número cada vez mayor de iniciativas para la conservación y uso sustentable de los arrecifes coralinos, en especial con las AMP. Para el INE 
Turismo: buceo y

conservación

(1997) entre los principios centrales para el manejo de las áreas arrecifales destaca:"Mantener una actividad turística de baja intensidad, con un volumen limitado de visitantes en apego a una capacidad de carga bien establecida." Para el manejo ambiental de los arrecifes de Cozumel está pendiente el objetivo de instrumentar la capacidad soporte de buzos y a pesar de que hay antecedentes relevantes en materia de indicadores relacionados con la densidad de visitantes (Frausto, 2002), los trabajos realizados a la fecha no incorporan las actividades específicas de buceo, motivo fundamental para la relevancia del proyecto propuesto.

Líneas de investigación

Considerando la relevancia que tiene el establecer la carga soporte de buzos por tipo de arrecife para Cozumel, se está desarrollando un programa de monitoreo de daños físicos producidos por contacto directo de los buzos con el arrecife. Con base en las experiencias derivadas de metodologías reportadas por el PNUMA (UNEP, 200I) se definió y está aplicando un programa de monitoreo con cuyos datos se efectuará el análisis estadístico de la información relativa a las variables seleccionadas. Las acciones y resultados contempladas en el proyecto son: formulación del protocolo de monitoreo; monitoreo de buzos; análisis estadístico de la información obtenida; propuesta de lineamientos adicionales para el manejo sustentable de la actividad turística de buceo en los arrecifes de Cozumel, y; análisis de la propuesta del PNUMA sobre capacidad soporte de buzos por arrecife con base en los resultados específicos del monitoreo realizado.

\section{Fuentes consultadas}

Coral (s/f) "Effective Coral Reef Marine Protected Areas: A solution for survival”, The Coral Reef Alliance. Consulta en www.cep.unep.org/ programmes/spaw/MPA

Frausto, Oscar et al. (2002). "Indicadores ambientales de turismo sustentable para el Caribe y Centroamérica: Isla de Cozumel, México”, en Pereira (2002).

-------- (2003). Desarrollo sustentable de la Isla de Cozumel:Turismo, negocios, costas, identidad y educación. México: UQROO, en prensa. 
INE (1997). Conservación y uso sustentable de los arrecifes en México: Logros y compromisos. México: INE

(1998). Programa de Manejo del Parque Marino Nacional Arrecifes de Cozumel. México: InE-Semarnap.

ONU (1992). Agenda 2 I. Consulta en sitio internet de la ONU.

Pereira, Alberto et al. (2002). Turismo, desarrollo y recursos naturales en el Caribe. México: Plaza y Váldes, UQROO y University of West Indies.

Santander, Luis Carlos (2003). "Desarrollo y turismo sustentable. Paradigmas, ideología y práctica social" en Frausto (2003)

Spalding, M. D. et al. (200 I). World Atlas of Coral Reefs. Berkeley: University of California Press.

UNEP (s/f). International Coral Reef Action Network (ICRAN)-Caribbean Region. Consulta en www.cep.unep.org/programmes/spaw/icran/ icran.htm

(200I). Tourism Impacts on Coral Reefs: Increasing awareness in the tourism sector. Consulta en sito internet www.cep.unep.org 


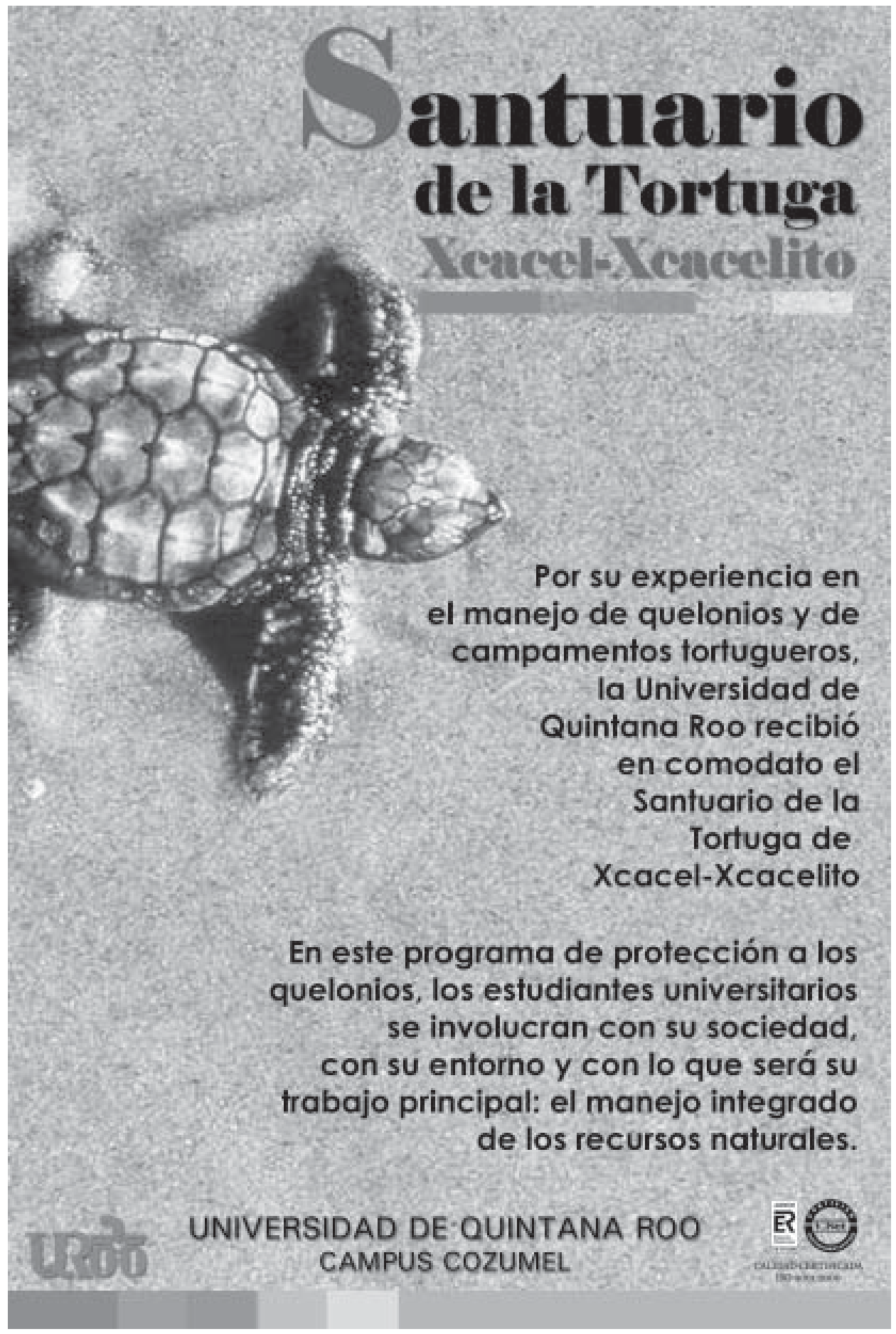

